\title{
Voltammetric Studies on the Mechanism of Electron Transfer Reactions at Liquid|liquid Interfaces
}

\author{
Hirosuke Tatsumi \\ International Young Researchers Empowerment Center, Shinshu University \\ Matsumoto, Nagano 390-8621, Japan
}

Received June 13, 2008, Accepted after Peer-Review June 26, 2008

\begin{abstract}
Theoretical equations of normal pulse, cyclic, and ac voltammetric currents of the electron transfer reaction at a liquid|liquid or organic solvent $(\mathrm{O})$ |water $(\mathrm{W})$ interface were derived under certain assumptions that are considered to be acceptable in most experimental systems employed for the study. Based on the theory, the mechanisms of the electron transfer reactions between bis(phthalocyaninato)lutetium $\quad\left(\left[\mathrm{Lu}(\mathrm{pc})_{2}\right]\right), \quad$ ferrocene $\left(\left[\mathrm{Fe}\left(\mathrm{C}_{5} \mathrm{H}_{5}\right)_{2}\right]\right), \quad$ or dibutylferrocene $\left(\left[\mathrm{Fe}\left(\mathrm{C}_{5} \mathrm{H}_{4} \mathrm{Bu}\right)_{2}\right]\right)$ in $\mathrm{O}$ and hexacyanoferrate redox couple $\left(\left[\mathrm{Fe}(\mathrm{CN})_{6}\right]^{3-/ 4-}\right)$ in $\mathrm{W}$ were determined experimentally. The theory and the experimental results are summarized in this review.
\end{abstract}

Keywords: Electron transfer; Liquid|liquid interfaces; Reaction mechanism; Polarography

\section{Introduction}

When a solute $\mathrm{A}$ in an organic solvent $(\mathrm{O})$ and another solute $\mathrm{B}$ in water (W) react at a liquid|liquid or $\mathrm{O} / \mathrm{W}$ interface of the two immiscible solutions, three reaction mechanisms can be supposed: (a) a heterogeneous reaction taking place at the $\mathrm{O} \mid \mathrm{W}$ interface, (b) a homogeneous reaction taking place in $\mathrm{O}$ phase associated with the transfer of $\mathrm{B}$ from $\mathrm{W}$ phase, and (c) a homogeneous reaction taking place in $\mathrm{W}$ phase associated with the transfer of $\mathrm{A}$ from $\mathrm{O}$ phase (Fig. 1). The mechanism can be studied by the use of voltammetry, if charge is transferred by the reaction. Kakutani et al. have employed ac voltammetry to study the mechanism of the transfer of sodium ion from $\mathrm{W}$ to nitrobenzene (NB) phase facilitated by dibenzo-18-crown-6 in $\mathrm{NB}$, indicating that the mechanism (a) in Fig. 1 is the most probable of the three. ${ }^{1)}$

Voltammetric studies on the mechanism of the electron transfer reaction at the $\mathrm{O} \mid \mathrm{W}$ interface between a redox couple $A_{R E D} / A_{O X}$ in $O$ phase and another redox couple $\mathrm{B}_{\mathrm{OX}} / \mathrm{B}_{\mathrm{RED}}$ in $\mathrm{W}$ phase have also been reported. Osakai and co-workers have studied the mechanism of the electron transfer reaction between ferrocene $\left(\left[\mathrm{Fe}\left(\mathrm{C}_{5} \mathrm{H}_{5}\right)_{2}\right]\right)$ in $\mathrm{NB}$ and hexacyanoferrate redox couple $\left(\left[\mathrm{Fe}(\mathrm{CN})_{6}\right]^{3-/ 4-}\right.$ ) in $\mathrm{W}$ by cyclic voltammetry, indicating that the 
reaction takes place by the mechanism (c) in Fig. $1 .^{2)}$ In previous papers, we have determined ${ }^{3-6)}$ the mechanisms of the electron transfer reactions between bis(phthalocyaninato)lutetium $\left(\left[\mathrm{Lu}(\mathrm{pc})_{2}\right]\right)$, $\left[\mathrm{Fe}\left(\mathrm{C}_{5} \mathrm{H}_{5}\right)_{2}\right]$, or dibutylferrocene $\left(\left[\mathrm{Fe}\left(\mathrm{C}_{5} \mathrm{H}_{4} \mathrm{Bu}\right)_{2}\right]\right)$ in $\mathrm{O}$ and $\left[\mathrm{Fe}(\mathrm{CN})_{6}\right]^{3-/ 4-}$ in $\mathrm{W}$, by using the theoretical equations of normal pulse, ${ }^{7)}$ cyclic, ${ }^{8)}$ and $\mathrm{ac}^{9)}$ voltammetric currents, which were derived under certain assumptions that are considered to be acceptable in most experimental systems employed for the study. The theory and the experimental results are summarized in this review.

(a)

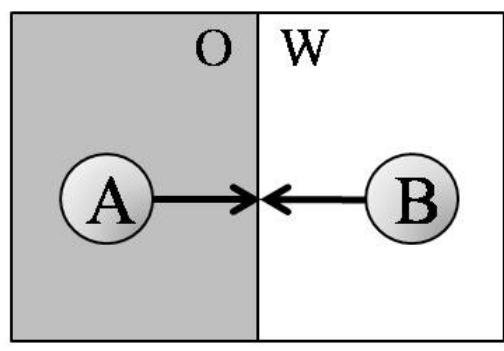

(b)

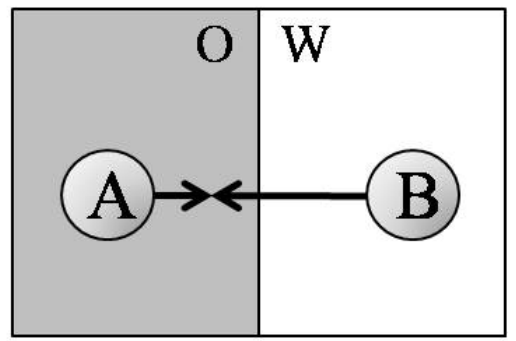

(c)

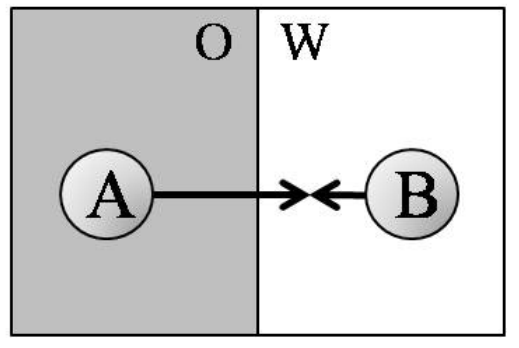

Fig. 1. Three reaction mechanisms at a liquid|liquid interface.

\section{Theory}

Let us consider the electron transfer reaction between a redox couple of $\mathrm{A}$ species in $\mathrm{O}$ phase, $\mathrm{A}_{\mathrm{RED}}(\mathrm{O}) / \mathrm{A}_{\mathrm{OX}}(\mathrm{O})$, and a redox couple of $\mathrm{B}$ species in $\mathrm{W}$ phase, $\mathrm{B}_{\mathrm{OX}}(\mathrm{W}) / \mathrm{B}_{\mathrm{RED}}(\mathrm{W})$, across the $\mathrm{O} / \mathrm{W}$ interface, where the suffixes RED and OX indicate the reduced and oxidized forms, respectively, of A and $\mathrm{B}$ species. Both $\mathrm{O}$ and $\mathrm{W}$ phases contain a large excess of supporting electrolyte and the reacting species are transported to and from the $\mathrm{O} \mid \mathrm{W}$ interface by diffusion. The linear semi-infinite diffusion is assumed. The electric double-layer effect is assumed to be negligible. In the following, we shall consider the case when $\mathrm{A}_{\mathrm{RED}}$ is a neutral molecule, while $\mathrm{A}_{\mathrm{OX}}$ is an $n^{+}$ cation where $n$ is the number of electrons transferred, e.g., $A_{\text {RED }}$ and $A_{O X}$ are ferrocene or its derivatives and their ferricenium ions, respectively. We also suppose that both $\mathrm{B}_{\mathrm{OX}}$ and $\mathrm{B}_{\mathrm{RED}}$ are highly hydrophilic ions, such as $\left[\mathrm{Fe}(\mathrm{CN})_{6}\right]^{3-}$ and $\left[\mathrm{Fe}(\mathrm{CN})_{6}\right]^{4-}$ ions. This allows us to ignore the transfer of $\mathrm{B}_{\mathrm{OX}}$ and $\mathrm{B}_{\mathrm{RED}}$ across the interface and to exclude the mechanism (b) in Fig. 1. Then, we may suppose the two mechanisms (a) and (c) of the electron transfer reaction. First, the electron transfer reaction may be the heterogeneous reaction that takes place at the $\mathrm{O} \mid \mathrm{W}$ interface according to ${ }^{10-14)}$

$\mathrm{A}_{\mathrm{RED}}(\mathrm{O})+\mathrm{B}_{\mathrm{OX}}(\mathrm{W})=\mathrm{A}_{\mathrm{OX}}(\mathrm{O})+\mathrm{B}_{\mathrm{RED}}(\mathrm{W})$,

which produces the electric current. Second, it may take place according to the mechanism as expressed by ${ }^{15)}$

$\mathrm{A}_{\mathrm{RED}}(\mathrm{O})=\mathrm{A}_{\mathrm{RED}}(\mathrm{W})$,

$\mathrm{A}_{\mathrm{RED}}(\mathrm{W})+\mathrm{B}_{\mathrm{OX}}(\mathrm{W})=\mathrm{A}_{\mathrm{OX}}(\mathrm{W})+\mathrm{B}_{\mathrm{RED}}(\mathrm{W})$,

$\mathrm{A}_{\mathrm{OX}}(\mathrm{W})=\mathrm{A}_{\mathrm{OX}}(\mathrm{O})$,

that is, the $\mathrm{A}_{\mathrm{RED}}(\mathrm{O})$ is transferred to $\mathrm{W}$ phase according to Eq. (2a), then the electron transfer reaction takes place in $\mathrm{W}$ phase according to Eq. (2b) while the electric current is associated with the succeeding ion transfer of $\mathrm{A}_{\mathrm{OX}}(\mathrm{W})$ to $\mathrm{O}$ phase 
across the $\mathrm{O} \mid \mathrm{W}$ interface according to Eq. (2c). In the following, we shall call ${ }^{2)}$ the first, heterogeneous electron transfer reaction mechanism by Eq. (1) the ET-mechanism, whereas the second, homogeneous electron transfer reaction associated with ion transfer mechanism by Eqs. $(2 \mathrm{a}-\mathrm{c})$ the IT-mechanism.

For the sake of simplicity, we assume that the bulk concentrations of $\mathrm{B}_{\mathrm{OX}}$ and $\mathrm{B}_{\mathrm{RED}}$ in $\mathrm{W}$ phase, ${ }^{*} c_{\mathrm{BO}}^{\mathrm{W}}$ and ${ }^{*} c_{\mathrm{BR}}^{\mathrm{W}}$, respectively, are sufficiently large compared with those of $\mathrm{A}_{\mathrm{RED}}$ and $\mathrm{A}_{\mathrm{OX}}$ in $\mathrm{O}$ phase, ${ }^{*} c_{\mathrm{AR}}^{\mathrm{O}}$ and ${ }^{*} c_{\mathrm{AO}}^{\mathrm{O}}$, that is, ${ }^{*} c_{\mathrm{BO}}^{\mathrm{W}},{ }^{*} c_{\mathrm{BR}}^{\mathrm{W}}>>^{*} c_{\mathrm{AR}}^{\mathrm{O}},{ }^{*} c_{\mathrm{AO}}^{\mathrm{O}}(=0$ in this study), so that the concentration polarization with respect to $\mathrm{B}_{\mathrm{OX}}$ and $\mathrm{B}_{\mathrm{RED}}$ species are negligibly small.

\section{1. Normal pulse voltammetry (NPV)}

The normal pulse voltammetric current of the electron transfer reaction $\left(I_{\mathrm{NPV}}\right)$ vs. the potential difference at the $\mathrm{O} \mid \mathrm{W}$ interface $\left(\Delta_{O}^{\mathrm{W}} \phi=\phi^{\mathrm{W}}-\phi^{\mathrm{O}}\right)$ is given by ${ }^{7,16)}$

$$
I_{\mathrm{NPV}}=I_{\mathrm{r}} \sqrt{\pi} \lambda \sqrt{t_{\mathrm{s}}} \exp \left[\lambda^{2} t_{\mathrm{s}}\right] \operatorname{erfc}\left[\lambda \sqrt{t_{\mathrm{s}}}\right],
$$

where

$$
I_{\mathrm{r}}=\frac{n F q \sqrt{D_{\mathrm{AR}}^{\mathrm{O}} / \pi t_{\mathrm{s}}}{ }^{*} c_{\mathrm{AR}}^{\mathrm{O}}}{1+\exp \left[-(n F / R T)\left(\Delta_{\mathrm{O}}^{\mathrm{W}} \phi-\Delta \phi_{1 / 2, \mathrm{r}}\right)\right]} .
$$

In these equations, $t_{\mathrm{S}}$ is the sampling time, $D_{\mathrm{AR}}^{\mathrm{O}}$ is the diffusion coefficients of $\mathrm{A}_{\mathrm{RED}}$ in $\mathrm{O}$ phase, and $\Delta \phi_{1 / 2, \mathrm{r}}$ is the reversible half-wave potential of the electron transfer reaction. $q$ is the surface area of the test interface, and $F, R$, and $T$ are used in the usual meanings. $\lambda$ is the kinetic parameter discussed below.

When a Butler-Volmer-type equation is adopted for Eq. (1), the $\lambda$-value for the ET-mechanism $\left(\lambda_{\mathrm{ET}}\right)$ is expressed by ${ }^{7,16)}$

$$
\begin{array}{r}
\lambda_{\mathrm{ET}}=\frac{\lambda_{\mathrm{ET}, 1 / 2}}{2}\left\{\exp \left[\frac{\alpha n F}{R T}\left(\Delta_{\mathrm{O}}^{\mathrm{W}} \phi-\Delta \phi_{1 / 2, \mathrm{r}}\right)\right]\right. \\
\left.+\exp \left[-\frac{\beta n F}{R T}\left(\Delta_{\mathrm{O}}^{\mathrm{W}} \phi-\Delta \phi_{1 / 2, \mathrm{r}}\right)\right]\right\},
\end{array}
$$

with

$\frac{\lambda_{\mathrm{ET}, 1 / 2}}{2}=k_{0}^{\mathrm{E}}\left(\frac{{ }^{*} c_{\mathrm{BO}}^{\mathrm{W}}}{\sqrt{D_{\mathrm{AR}}^{\mathrm{O}}}}\right)^{\beta}\left(\frac{{ }^{*} c_{\mathrm{BR}}^{\mathrm{W}}}{\sqrt{D_{\mathrm{AO}}^{\mathrm{O}}}}\right)^{\alpha}$,

where $k_{0}^{\mathrm{E}}$ is the standard rate constant of the Bulter-Volmer-type equation, and $\alpha$ and $\beta(\alpha+\beta$ $=1$ ) are the transfer coefficients of the forward and backward rate constants, respectively.

In discussing the $\lambda$-value for the IT-mechanism $\left(\lambda_{\mathrm{IT}}\right)$, two more assumptions are introduced: (i) the partition coefficient of $\mathrm{A}_{\mathrm{RED}}, K_{\mathrm{p}}$, is sufficiently large, so that $K^{\prime} K_{\mathrm{p}}>1$ even when $K^{\prime}<1\left(K^{\prime}=k_{\mathrm{b}}{ }^{\mathrm{I}}\right.$ ${ }^{*} c_{\mathrm{BR}}^{\mathrm{W}} / k_{\mathrm{f}}^{\mathrm{I}}{ }^{*} c_{\mathrm{BO}}^{\mathrm{W}}$ ), and (ii) the forward and backward rate constants of Eq. (2b), $k_{\mathrm{f}}^{\mathrm{I}}$ and $k_{\mathrm{b}}^{\mathrm{I}}$, respectively, are so large that $\left(k_{\mathrm{f}}^{\mathrm{I}}{ }^{*} c_{\mathrm{BO}}^{\mathrm{W}}+k_{\mathrm{b}}^{\mathrm{I}}{ }^{*} c_{\mathrm{BR}}^{\mathrm{W}}\right) t_{\mathrm{s}}>1$. Furthermore, the IT-mechanism may be conveniently classified into three cases A1, A2, and $\mathrm{B}$ according to the rate-determining step in Eqs. $(2 a-c){ }^{7)}$ When the step of Eq. (2b) is rate-determining while the steps of Eqs. (2a) and (2c) are nernstian (Case A2), then the kinetic parameter $\left(\lambda_{\mathrm{IT}, \mathrm{A} 2}\right)$ is expressed by ${ }^{7)}$

$$
\lambda_{\mathrm{IT}, \mathrm{A} 2}=\frac{\lambda_{\mathrm{IT}, \mathrm{A} 2,1 / 2}}{2}\left\{1+\exp \left[-\frac{n F}{R T}\left(\Delta_{\mathrm{O}}^{\mathrm{W}} \phi-\Delta \phi_{1 / 2, \mathrm{r}}\right)\right]\right\} \text {, }
$$

where

$$
\frac{\lambda_{\mathrm{IT}, \mathrm{A} 2,1 / 2}}{2}=\frac{\sqrt{k_{\mathrm{f}}^{\mathrm{I}}{ }^{*} c_{\mathrm{BO}}^{\mathrm{W}}}}{K_{\mathrm{p}} \sqrt{1+K^{\prime}}} \sqrt{\frac{D_{\mathrm{A}}^{\mathrm{W}}}{D_{\mathrm{AR}}^{\mathrm{O}}}},
$$

and $D_{\mathrm{A}}^{\mathrm{W}}$ is the common diffusion coefficient of $\mathrm{A}_{\text {RED }}$ and $\mathrm{A}_{\mathrm{OX}}$ in the $\mathrm{W}$ phase. For Cases $\mathrm{A} 1$ and $\mathrm{B}$, see Ref. 7.

When the electron transfer reaction takes place by both the ET- and IT-mechanisms in parallel, the $\lambda$-value is expressed by ${ }^{7}$

$\lambda=\lambda_{\mathrm{ET}}+\lambda_{\mathrm{IT}}$

The voltammetric behavior of electron transfer reaction at $\mathrm{O} \mid \mathrm{W}$ interface is explained by the ET-mechanism when $\lambda_{\mathrm{ET}}>\lambda_{\mathrm{IT}}$, whereas it is explained by the IT-mechanism when $\lambda_{\mathrm{ET}}<<\lambda_{\mathrm{IT}}$. 


\subsection{Cyclic voltammetry $(\mathrm{CV})$}

The cyclic voltammetric current of the electron transfer reaction $\left(I_{\mathrm{CV}}\right)$ is given by ${ }^{8,16)}$

$$
\begin{aligned}
I_{\mathrm{CV}}= & n F q \sqrt{D_{\mathrm{AR}}^{\mathrm{O}}} \sqrt{\frac{n F v}{R T}} *^{\mathrm{O}} \\
& \times \Psi_{\Lambda, \alpha}\left[\frac{n F}{R T}\left(\Delta_{\mathrm{O}}^{\mathrm{W}} \phi-\Delta \phi_{1 / 2, \mathrm{r}}\right)\right]
\end{aligned}
$$

Here, $v$ is the rate of the potential sweep, and $\Psi_{\Lambda, \alpha}$ is Matsuda's $\Psi$-function, ${ }^{17)}$ where the numerical integration should be extended to cover the backward sweep range of the applied potential. ${ }^{18,19)}$ The suffixes $\Lambda$ and $\alpha$ indicate that the $\Psi$-function is dependent on these kinetic parameters, where $\Lambda$ both for the ET- and IT-mechanisms is defined by $^{8,16)}$

$\Lambda=\frac{\lambda_{\mathrm{m}, 1 / 2}}{2} / \sqrt{\frac{n F v}{R T}} \quad(\mathrm{~m}=$ ET or IT $)$.

For Cases A1 and A2 of the IT-mechanism, $\alpha=$ $0 .^{16)}$

\subsection{AC voltammetry ( $A C V$ )}

When the rates of the electron transfer reaction are rather high that the electron transfer reaction is dc-voltammetric-reversible, the ac voltammetric current $\left(I_{\mathrm{ACV}}\right)$ at the quasi-stationary state is related to the applied ac voltage $\left(E_{\mathrm{ac}}\right)$ by ${ }^{9)}$

$$
I_{\mathrm{ACV}}=\frac{E_{\mathrm{ac}}}{\sqrt{2} \sigma / \lambda+(1-\mathrm{j}) \sigma / \sqrt{\omega}},
$$

where

$$
\sigma=\frac{4 R T \cosh ^{2}\left[(n F / 2 R T)\left(\Delta_{\mathrm{O}}^{\mathrm{W}} \phi-\Delta \phi_{1 / 2, \mathrm{r}}\right)\right]}{n^{2} F^{2} q \sqrt{2 D_{\mathrm{AR}}^{\mathrm{O}}}{ }^{*} c_{\mathrm{AR}}^{\mathrm{O}}} .
$$

In these equations, $\mathrm{j}$ is the imaginary unit and $\omega$ is the angular frequency. The kinetic parameter $\lambda$ in Eq. (9a) is discussed above (Eqs. (4a)-(6)).

\section{Experimental Results}

\section{1. $\left[\mathrm{Lu}(\mathrm{pc})_{2}\right](1,2-\mathrm{DCE}) \mid\left[\mathrm{Fe}(\mathrm{CN})_{6}\right]^{3-/ 4-}(\mathrm{W})$}

The electron transfer reaction between

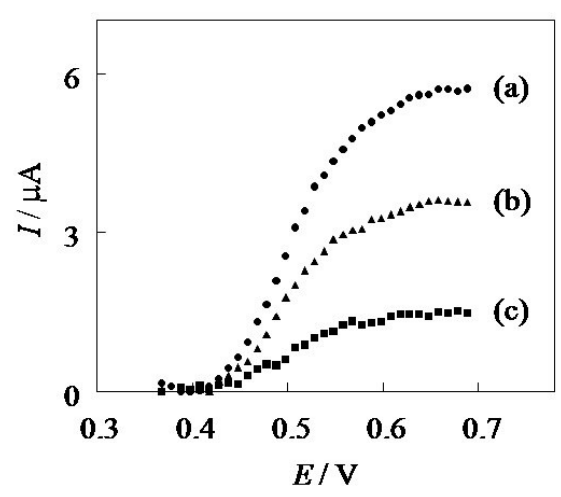

Fig. 2. Normal pulse voltammograms of the electron transfer between $\left[\mathrm{Lu}(\mathrm{pc})_{2}\right]$ in 1,2-DCE and $\left[\mathrm{Fe}(\mathrm{CN})_{6}\right]^{3-/ 4-}$ in $\mathrm{W}$ recorded at $t_{\mathrm{s}}=0.016(\mathrm{a}, \bullet)$, $0.040(\mathrm{~b}, \mathbf{\Delta})$, and $0.25 \mathrm{~s} \mathrm{(c,} \mathbf{\square})$ when ${ }^{*} c_{\mathrm{AR}}^{\mathrm{O}}=0.08 \mathrm{mM}$ and ${ }^{*} c_{\mathrm{BO}}^{\mathrm{W}}={ }^{*} c_{\mathrm{BR}}^{\mathrm{W}}=4.0 \mathrm{mM}^{6}{ }^{6}$

$\left[\mathrm{Lu}(\mathrm{pc})_{2}\right]$ in 1,2-dichloroethane (1,2-DCE) and $\left[\mathrm{Fe}(\mathrm{CN})_{6}\right]^{3-/ 4-}$ in $\mathrm{W}$ has been studied first by Schiffrin and his co-workers. ${ }^{20,21)}$ This reaction has been believed to proceed by the ET-mechanism, although the experimental evidence for the reaction mechanism has not been shown. We have applied NPV and ACV to determine the mechanism. ${ }^{6)}$

In NPV, S-shaped voltammograms with well-defined limiting currents were obtained when ${ }^{*} c_{\mathrm{AR}}^{\mathrm{O}}=0.08 \mathrm{mM}$ and ${ }^{*} c_{\mathrm{BO}}^{\mathrm{W}}={ }^{*} c_{\mathrm{BR}}^{\mathrm{W}}=4.0 \mathrm{mM}$ (Fig. 2). Here, the applied potential $(E)$ is related to $\Delta_{\mathrm{O}}^{\mathrm{W}} \phi$ by

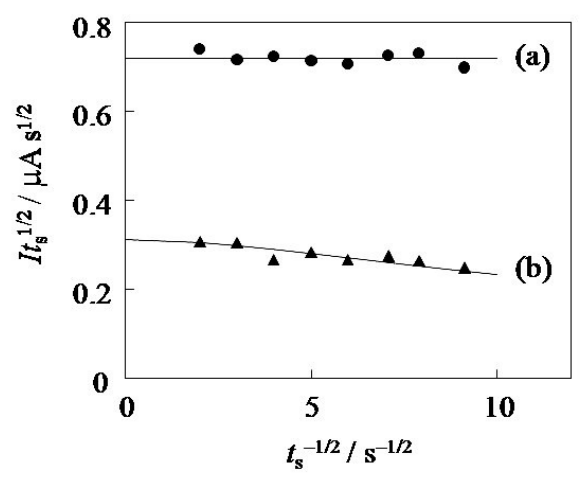

Fig. 3. Plots of $I_{1} t_{\mathrm{s}}{ }^{1 / 2}(\mathrm{a}, \bullet)$ and $I_{1 / 2} t_{\mathrm{s}}{ }^{1 / 2}(\mathrm{~b}$, against $t_{\mathrm{s}}^{-1 / 26)}$ 
$E=\Delta_{O}^{\mathrm{W}} \phi+\Delta E_{\text {ref, }}$, where $\Delta E_{\text {ref }}$ depends on the reference electrode system and was determined to be $0.445 \mathrm{~V}^{4-6)}$ The limiting currents $\left(I_{1}\right)$ were determined at several $t_{\mathrm{s}}$ 's $(0.012-0.25 \mathrm{~s})$, and the $I_{1} t_{\mathrm{s}}{ }^{1 / 2}$-values gave a nearly constant value, indicating that the limiting current is diffusion-controlled (Fig. 3(a)). On the other hand, the $I_{1 / 2} t_{\mathrm{s}}^{1 / 2}$-values, where $I_{1 / 2}$ is the current when the reversible half-wave potential was applied to the interface, tended to decrease with increasing $t_{\mathrm{s}}^{-1 / 2}$ (Fig. 3(b)). However, it was difficult to determine the accurate value of $\lambda$ from Eq. (3a), because the deviation from $I_{\mathrm{r}}$ was very small.

In ACV, bell-shaped ac voltammograms were obtained when ${ }^{*} c_{\mathrm{AR}}^{\mathrm{O}}=0.08 \mathrm{mM}$ and ${ }^{*} c_{\mathrm{BO}}^{\mathrm{W}}={ }^{*}{ }^{\mathrm{W}} \mathrm{WR}=$ $4.0-8.0 \mathrm{mM}$. The real and imaginary components of the admittance attributable to the electron transfer reaction were transformed to a series combination of a resistance $R_{\mathrm{s}}$ and a capacitance $C_{\mathrm{s}}$, and analyzed by the use of Randles-plot method. ${ }^{9)}$ The plots of $R_{\mathrm{S}}$ and $1 / \omega C_{\mathrm{s}}$ at the reversible half-wave potential $\left(E_{1 / 2, \mathrm{r}}=0.486 \mathrm{~V}\right)$ against $\omega^{-1 / 2}$ gave straight lines with common slope $(\sigma)$, and the $R_{\mathrm{S}}$ vs. $\omega^{-1 / 2}$ plot gave a positive intercept $(\theta)$, whereas the $1 / \omega C_{\mathrm{s}}$ vs. $\omega^{-1 / 2}$ plot gave a nearly-zero intercept. From the slope and the intercept, $D_{\mathrm{AR}}^{\mathrm{O}}$ and $\lambda(=\sqrt{2} \sigma / \theta)$ were calculated and are summarized in Table 1 . With increasing ${ }^{*} c_{\mathrm{BO}}^{\mathrm{W}}(=$ $\left.{ }^{*}{ }^{*} \mathrm{~W}\right)$ by 1.5 times, the $\lambda$-value increased by about 1.7 times. Furthermore, the $\lambda$-values at several applied dc potentials $\left(E_{\mathrm{dc}}\right)$ were determined for ${ }^{*} c_{\mathrm{BO}}^{\mathrm{W}}={ }^{*} c_{\mathrm{BR}}^{\mathrm{W}}=4.0 \mathrm{mM}$ and are shown in Fig. 4 . The

Table 1. Diffusion coefficients of $\left[\mathrm{Lu}(\mathrm{pc})_{2}\right]$ in 1,2 -DCE and the $\lambda$-values at $E_{\mathrm{dc}}=E_{1 / 2, \mathrm{r}}=0.486 \mathrm{~V}$ determined by $\mathrm{ACV}^{6}$

\begin{tabular}{cccc}
\hline${ }^{*} c_{\mathrm{BO}}^{\mathrm{W}}\left(={ }^{*} c_{\mathrm{BR}}^{\mathrm{W}}\right) / \mathrm{mM}$ & 4.0 & 6.0 & 8.0 \\
\hline$D_{\mathrm{AR}}^{\mathrm{O}} / 10^{-6} \mathrm{~cm}^{2} \mathrm{~s}^{-1}$ & $4.4 \pm 0.5$ & $3.9 \pm 0.9$ & $4.0 \pm 1.3$ \\
$\lambda / \mathrm{s}^{-1 / 2}$ & $60 \pm 13$ & $105 \pm 61$ & - \\
\hline
\end{tabular}

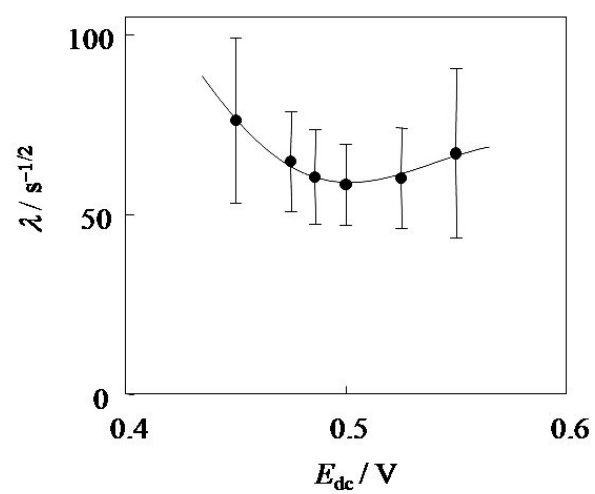

Fig. 4. Plot of the $\lambda$-values against $E_{\mathrm{dc}}$ when ${ }^{*} c_{\mathrm{BO}}^{\mathrm{W}}=$ ${ }^{*} c_{\mathrm{BR}}^{\mathrm{W}}=4.0 \mathrm{mM}$. Vertical bars indicate the $95 \%$ confidence intervals. ${ }^{6)}$

$\lambda$-value had a minimum value at around $E_{\mathrm{dc}}=E_{1 / 2, \mathrm{r}}$. A similar $\lambda$ vs. $E_{\mathrm{dc}}$ plot with a minimum value at around $E_{\mathrm{dc}}=E_{1 / 2, \mathrm{r}}$ was obtained for ${ }^{*} c_{\mathrm{BO}}^{\mathrm{W}}={ }^{*} c_{\mathrm{BR}}^{\mathrm{W}}=$ $6.0 \mathrm{mM}$.

The above voltammetric results were most likely explained by the theoretical equations for the ET-mechanism, Eq. (4a), which predicts that the $\lambda$ vs. $E_{\mathrm{dc}}$ plot has a minimum value at around $E_{\mathrm{dc}}=$ $E_{1 / 2, \mathrm{r}}$ when $\alpha$ is around $0.5,{ }^{21)}$ and Eq. (4b), which predicts that the $\lambda$-value is proportional to ${ }^{*} c_{\mathrm{BO}}^{\mathrm{W}}$ when ${ }^{*}{ }^{*} \mathrm{~W}$ theoretical equations for Cases $\mathrm{A} 1$ and $\mathrm{A} 2$ of the IT-mechanism, ${ }^{7,9)}$ which predict that the $\lambda$-value decreases with increasing $E_{\mathrm{dc}}$-value and approaches a limiting value (see Eq. (5a) for Case A2), and those for Case B of the IT-mechanism, ${ }^{7,9)}$ which predict that the $\lambda$-value is independent of ${ }^{*}{ }_{\mathrm{BO}}^{\mathrm{W}}$, are not in agreement with the experimental results. Thus, it is concluded that the electron transfer reaction between $\left[\mathrm{Lu}(\mathrm{pc})_{2}\right]$ in 1,2-DCE and $\left[\mathrm{Fe}(\mathrm{CN})_{6}\right]^{3-/ 4-}$ in $\mathrm{W}$ at the $1,2-\mathrm{DCE} \mid \mathrm{W}$ interface takes place by the ET-mechanism according to Eq. (1). The kinetic parameters of the heterogeneous electron transfer reaction were determined. ${ }^{6)}$ 
3.2. $\left[\mathrm{Fe}\left(\mathrm{C}_{5} \mathrm{H}_{5}\right)_{2}\right](1,2-\mathrm{DCE}$ or $\mathrm{NB})$ or $\left[\mathrm{Fe}\left(\mathrm{C}_{5} \mathrm{H}_{4} \mathrm{Bu}\right)_{2}\right](1,2-\mathrm{DCE}) \mid\left[\mathrm{Fe}(\mathrm{CN})_{6}\right]^{3-14-}(\mathrm{W})$

The electron transfer reaction between $\left[\mathrm{Fe}\left(\mathrm{C}_{5} \mathrm{H}_{5}\right)_{2}\right]$ in $\mathrm{NB}$ and $\left[\mathrm{Fe}(\mathrm{CN})_{6}\right]^{3-/ 4-}$ in $\mathrm{W}$ has been studied first by Samec and his co-workers. ${ }^{10,13)}$ Osakai and his co-workers have applied the digital simulation technique to analyze cyclic voltammograms of this reaction, showing that the reaction takes place by the IT-mechanism. ${ }^{2}$ We have also shown by the use of $\mathrm{NPV}$ that the reaction both at 1,2-DCE|W and $\mathrm{NB} \mid \mathrm{W}$ interfaces takes place by the IT-mechanism, which is in harmony with the conclusion by Osakai et al. (see Ref. 5 for detail). Here, the experimental results of NPV of the electron transfer reaction between $\left[\mathrm{Fe}\left(\mathrm{C}_{5} \mathrm{H}_{4} \mathrm{Bu}\right)_{2}\right]$ in 1,2-DCE and $\left[\mathrm{Fe}(\mathrm{CN})_{6}\right]^{3-/ 4-}$ in $\mathrm{W}^{4)}$ are summarized.

Figure 5 shows the normal pulse voltammograms recorded at a constant sampling time of $t_{\mathrm{s}}=0.1 \mathrm{~s}$ when ${ }^{*} c_{\mathrm{AR}}^{\mathrm{O}}=0.70 \mathrm{mM}$ and ${ }^{*} c_{\mathrm{BO}}^{\mathrm{W}}=$ ${ }^{*}{ }^{*} \mathrm{~W}=0.010$ and $0.10 \quad$ M. S-shaped current-potential curves with well-defined limiting currents were observed. The limiting currents $\left(I_{1}\right)$ observed at $E=0.66 \mathrm{~V}$ decreased with decreasing

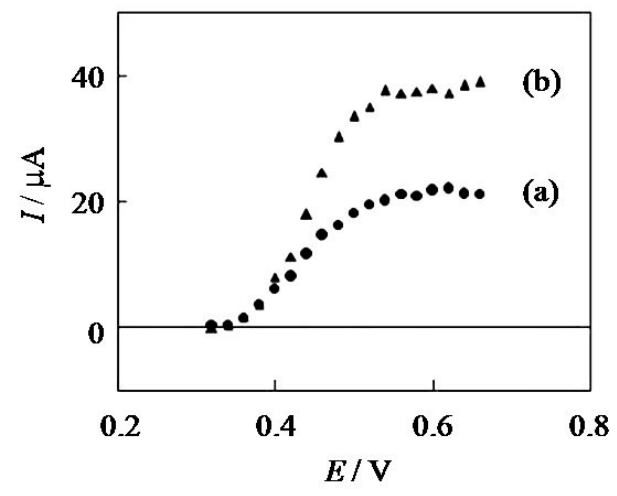

Fig. 5. Normal pulse voltammograms of the electron transfer between $\left[\mathrm{Fe}\left(\mathrm{C}_{5} \mathrm{H}_{4} \mathrm{Bu}\right)_{2}\right]$ in 1,2-DCE and $\left[\mathrm{Fe}(\mathrm{CN})_{6}\right]^{3-/ 4-}$ in $\mathrm{W}$ recorded at $t_{\mathrm{s}}=0.1 \mathrm{~s}$ when ${ }^{*} c_{\mathrm{AR}}^{\mathrm{O}}=$ $0.70 \mathrm{mM}$ and ${ }^{*} c_{\mathrm{BO}}^{\mathrm{W}}={ }^{*} c_{\mathrm{BR}}^{\mathrm{W}}=0.010(\mathrm{a}, \bullet)$ and $0.10 \mathrm{M}$ $(\mathrm{b}, \mathbf{\Delta}){ }^{4)}$

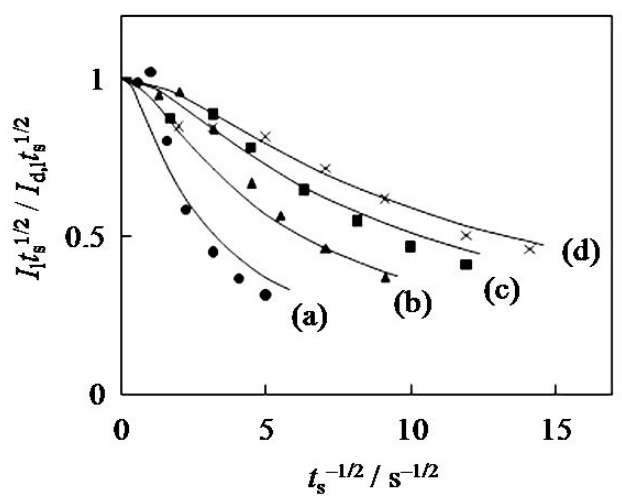

Fig. 6. Plots of $I_{1} t_{\mathrm{s}}^{1 / 2}$ against $t_{\mathrm{s}}^{-1 / 2}$ when ${ }^{*} c_{\mathrm{BO}}^{\mathrm{W}}={ }^{*} c_{\mathrm{BR}}^{\mathrm{W}}=$ $0.010(\mathrm{a}, \bullet), 0.040(\mathrm{~b}, \boldsymbol{\Delta}), 0.070(\mathrm{c}, \mathbf{a})$, and $0.10 \mathrm{M}$ $(\mathrm{d}, \times)$. The ordinate is normalized by the limiting diffusion current $\left.\left(I_{\mathrm{d}, 1} t_{\mathrm{s}}^{1 / 2}=n F q\left(D_{\mathrm{AR}}^{\mathrm{O}} / \pi\right)^{1 / 2 *} c_{\mathrm{AR}}^{\mathrm{O}}\right){ }^{4}\right)$

${ }^{*} c_{\mathrm{BO}}^{\mathrm{W}}\left(={ }^{*} c_{\mathrm{BR}}^{\mathrm{W}}\right)$. Furthermore, as shown in Fig. 6, they largely deviated from the limiting diffusion current $\left(I_{\mathrm{d}, 1}\right)$ with increasing $t_{\mathrm{s}}^{-1 / 2}$, in contrast to the experimental result of the electron transfer reaction between $\quad\left[\mathrm{Lu}(\mathrm{pc})_{2}\right](1,2-\mathrm{DCE}) \quad$ and $\left[\mathrm{Fe}(\mathrm{CN})_{6}\right]^{3-/ 4-}(\mathrm{W})$ shown above (Fig. 3(a)). In Fig. 6 , the solid lines are the fitted curves by Eq. (3a), from which $\lambda$-values were determined to be $1.4 \pm 0.4,2.7 \pm 0.8,4.5 \pm 1.5$, and $5.8 \pm 2.0 \mathrm{~s}^{-1 / 2}$ when ${ }^{*} c_{\mathrm{BO}}^{\mathrm{W}}={ }^{*} c_{\mathrm{BR}}^{\mathrm{W}}=0.010,0.040,0.070$, and $0.10 \mathrm{M}$, respectively. In Fig. 7 , the $\lambda$-values at $E=0.66 \mathrm{~V}$

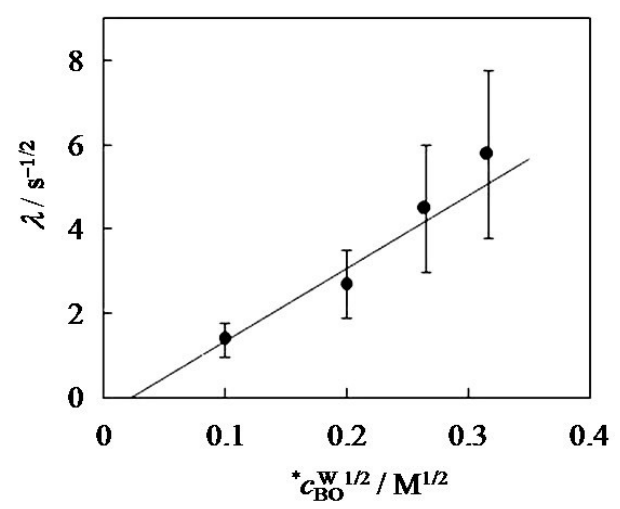

Fig. 7. Plot of the $\lambda$-values at $E=0.66 \mathrm{~V}$ against ${ }^{*} c_{\mathrm{BO}}^{\mathrm{W}}{ }^{1 / 2}$. Vertical bars indicate the $95 \%$ confidence intervals. ${ }^{4}$ 


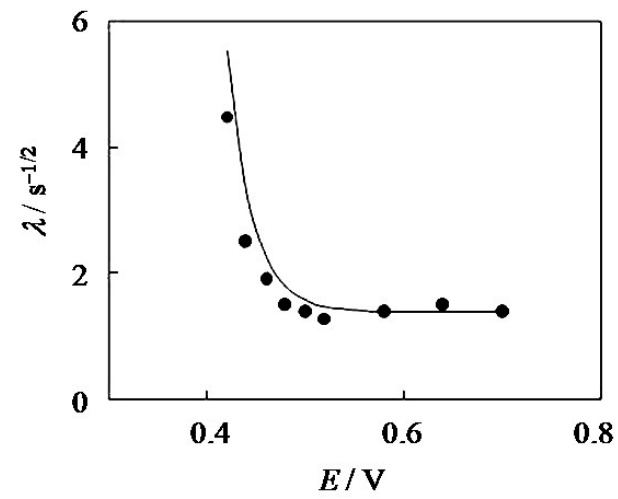

Fig. 8. Plot of the $\lambda$-values against $E$ when ${ }^{*} c_{\mathrm{BO}}^{\mathrm{W}}=$ ${ }^{*} c_{\mathrm{BR}}^{\mathrm{W}}=0.010 \mathrm{M}^{4)}$

are plotted against the square root of ${ }^{*} c_{\mathrm{BO}}^{\mathrm{W}}\left(={ }^{*} c_{\mathrm{BR}}^{\mathrm{W}}\right)$, indicating that the $\lambda$-values is proportional to the square root of ${ }^{*} c_{\mathrm{BO}}^{\mathrm{W}}$, but not to ${ }^{*} c_{\mathrm{BO}}^{\mathrm{W}}$ itself. In Fig. 8, the $\lambda$-values are plotted against $E$ when ${ }^{*} c_{\mathrm{BO}}^{\mathrm{W}}={ }^{*} c_{\mathrm{BR}}^{\mathrm{W}}$ $=0.010 \mathrm{M}$. With increasing $E$, the $\lambda$-values decreased and approached a limiting value, in contrast to the result of the electron transfer reaction between $\left[\mathrm{Lu}(\mathrm{pc})_{2}\right](1,2-\mathrm{DCE})$ and $\left[\mathrm{Fe}(\mathrm{CN})_{6}\right]^{3-/ 4-}(\mathrm{W})$ shown above (Fig. 4). The calculated values of $\lambda_{\mathrm{IT}, \mathrm{A} 2}$ by Eq. (5a) with $\lambda_{\mathrm{IT}, \mathrm{A} 2,1 / 2} / 2=1.4 \mathrm{~s}^{-1 / 2}$ and $E_{1 / 2, \mathrm{r}}=0.448 \mathrm{~V}$ are shown by the solid line in Fig. 8, which are in agreement with the experimental ones.

The above voltammetric results were explained well by the theoretical equations for Case A2 of the IT-mechanism, Eq. (5a), which predicts that the $\lambda$-value decreases with increasing $E$-value and approaches a limiting value, and Eq. (5b), which predicts that the $\lambda$-value is proportional to the square root of ${ }^{*} c_{\mathrm{BO}}^{\mathrm{W}}$ when ${ }^{*} c_{\mathrm{BO}}^{\mathrm{W}}={ }^{*} c_{\mathrm{BR}}^{\mathrm{W}}$. Thus, it is concluded that the electron transfer reaction between $\left[\mathrm{Fe}\left(\mathrm{C}_{5} \mathrm{H}_{4} \mathrm{Bu}\right)_{2}\right]$ in 1,2-DCE and $\left[\mathrm{Fe}(\mathrm{CN})_{6}\right]^{3-/ 4-}$ in $\mathrm{W}$ at the $1,2-\mathrm{DCE} \mid \mathrm{W}$ interface takes place by the IT-mechanism according to Eqs. $(2 \mathrm{a}-\mathrm{c})$, and the step of Eq. ( $2 \mathrm{~b})$ is rate-determining.

\section{Conclusions}

When NPV, CV, or ACV of the electron transfer reaction between $\mathrm{A}_{\mathrm{RED}}(\mathrm{O}) / \mathrm{A}_{\mathrm{OX}}(\mathrm{O})$ and $\mathrm{B}_{\mathrm{OX}}(\mathrm{W}) / \mathrm{B}_{\mathrm{RED}}(\mathrm{W})$ at $\mathrm{O} \mid \mathrm{W}$ interface is performed under the condition where the pseudo-first-order reaction with respect to $A_{R E D}$ and $A_{O X}$ is satisfied, the dependence of the obtained $\lambda$-value on ${ }^{*} c_{\mathrm{BO}}^{\mathrm{W}}$ and on $\Delta_{O}^{\mathrm{W}} \phi$ (and thus $E$ ) indicates whether the reaction proceeds by way of the ET- or the IT-mechanism. By this method, the mechanisms of the electron transfer reaction between $\left[\mathrm{Lu}(\mathrm{pc})_{2}\right](1,2-\mathrm{DCE})$ and $\left[\mathrm{Fe}(\mathrm{CN})_{6}\right]^{3-/ 4-}(\mathrm{W})$ and that between $\left[\mathrm{Fe}\left(\mathrm{C}_{5} \mathrm{H}_{5}\right)_{2}\right](1,2-\mathrm{DCE}$ or $\mathrm{NB})$ or $\left[\mathrm{Fe}\left(\mathrm{C}_{5} \mathrm{H}_{4} \mathrm{Bu}\right)_{2}\right](1,2-\mathrm{DCE})$ and $\left[\mathrm{Fe}(\mathrm{CN})_{6}\right]^{3-/ 4-}(\mathrm{W})$ were determined to be ET and IT, respectively. In most experimental systems employed for the study, $K_{\mathrm{p}}$ may be one of the most critical factors that control the mechanism. Now the study is being extended to other redox couples.

\section{Acknowledgements}

The author would like to thank Professors Mitsugi Senda and Hajime Katano for fruitful discussions. This study was performed through a Grant-in-Aid for Scientific Research from the Fukui Prefecture University Science Foundation, Grants-in-Aid for Young Scientists (No. 16780086 and 18780077), and Special Coordination Funds for Promoting Science and Technology of the Ministry of Education, Culture, Sports, Science and Technology, the Japanese Government.

\section{References}

1) T. Kakutani, Y. Nishiwaki, T. Osakai, and M. Senda, On the mechanism of transfer of sodium ion across the nitrobenzene/water interface facilitated by dibenzo-18-crown-6, Bull. Chem. Soc. Jpn., 59, 781 (1986).

2) H. Hotta, S. Ichikawa, T. Sugihara, and T. 
Osakai, Clarification of the mechanism of interfacial electron-transfer reaction between ferrocene and hexacyanoferrate(III) by digital simulation of cyclic voltammograms, J. Phys. Chem. B, 107, 9717 (2003).

3) H. Tatsumi and H. Katano, Voltammetric study of the interfacial electron transfer between bis(cyclopentadienyl)iron in organic solvents and hexacyanoferrate in water, Anal. Sci., 20, 1613 (2004).

4) H. Tatsumi and H. Katano, Voltammetric study of the interfacial electron transfer between bis(butylcyclopentadienyl)iron in 1,2-dichloroethane and hexacyanoferrate in water, J. Electroanal. Chem., 577, 59 (2005).

5) H. Tatsumi and H. Katano, Voltammetric study of the interfacial electron transfer between bis(cyclopentadienyl)iron in 1,2-dichloroethane and in nitrobenzene and hexacyanoferrate in water, $J$. Electroanal. Chem., 592, 121 (2006).

6) H. Tatsumi and H. Katano, Voltammetric study of the interfacial electron transfer between bis(phthalocyaninato)lutetium in 1,2-dichloroethane and hexacyanoferrate in water, J. Electroanal. Chem., 614, 61 (2008).

7) H. Tatsumi, H. Katano, and M. Senda, Theory of normal-pulse voltammetric current of electron transfer reaction at liquid/liquid interface, J. Electroanal. Chem., 590, 82 (2006).

8) H. Tatsumi and H. Katano, Cyclic voltammetry of the electron transfer reaction between bis(cyclipentadienyl)iron in 1,2-dichloroethane and hexacyanoferrate in water, Anal. Sci., 23, 589 (2007).

9) H. Tatsumi, H. Katano, and M. Senda, Theory of ac-voltammetric current of electron transfer reaction at liquid|liquid interface, $J$.
Electroanal. Chem., 615, 45 (2008).

10) Z. Samec, V. Mareček, and J. Weber, Detection of an electron transfer across the interface between two immiscible electrolyte solutions by cyclic voltammetry with four-electrode system, J. Electroanal. Chem., 96, 245 (1979).

11) Z. Samec, Charge transfer between two immiscible electrolyte solutions: Part I. Basic equation for the rate of the charge transfer across the interface, J. Electroanal. Chem., 99, 197 (1979).

12) Z. Samec, Charge transfer between two immiscible electrolyte solutions: Part III. Stationary curve of current vs. potential of electron transfer across interface, $J$. Electroanal. Chem., 103, 1 (1979).

13) Z. Samec, V. Mareček, and J. Weber, Charge transfer between two immiscible electrolyte solutions: Part IV. Electron transfer between hexacyanoferrate(III) in water and ferrocene in nitrobenzene investigated by cyclic voltammetry with four-electrode system, $J$. Electroanal. Chem., 103, 11 (1979).

14) Z. Samec, V. Mareček, J. Weber, and D. Homolka, Charge transfer between two immiscible electrolyte solutions: Part VII. Convolution potential sweep voltammetry of $\mathrm{Cs}^{+}$ion transfer and of electron transfer between ferrocene and hexacyanoferrate(III) ion across the water/nitrobenzene interface, $J$. Electroanal. Chem., 126, 105 (1981).

15) J. Hanzlík, Z. Samec, and J. Hovorka, Transfer of ferricenium cation across water/organic solvent interfaces, J. Electroanal. Chem., 216, 303 (1987).

16) M. Senda, Theory of voltammetric current of electron transfer across liquid/liquid interface, Rev. Polarogr., 49, 219 (2003); ibid., 50, 60 
(2004) (corrections).

17) H. Matsuda und Y. Ayabe, Zur Theorie der Randles-Sevčikschen

Kathodenstrahl-

Polarographie, Z. Elektrochem., 59, 494 (1955).

18) R. S. Nicholson and I. Shain, Theory of stationary electrode polarography: Single scan and cyclic methods applied to reversible, irreversible, and kinetic systems, Anal. Chem., 36, 706 (1964).

19) R. S. Nicholson, Theory and application of cyclic voltammetry for measurement of electrode reaction kinetics, Anal. Chem., 37, 1351 (1965).

20) G. Geblewicz and D. J. Schiffrin, Electron transfer between immiscible solutions: The hexacyanoferrate-lutetium biphthalocyanine system, J. Electroanal. Chem., 244, 27 (1988).

21) Y. Cheng and D. J. Schiffrin, A.C. impedance study of rate constants for two-phase electron-transfer reactions, J. Chem. Soc. Faraday Trans., 89, 199 (1993). 